\title{
Discussion on the advantages of Experimental Teaching of Medical Laboratory under the Mode of Integration of Department and subject
}

\author{
Yan Zhao, Ying Liu, Hongjuan Song, Fengying Zheng, Hong Xu \\ Department of Medicine, Binzhou Polytechnic College, Binzhou, 256600, Shandong, China \\ Email: zhaoyanyan2006@126.com,
}

\begin{abstract}
Keywords: Combination of Department and subject; Medical examination; Advantage of Experimental Teaching
\end{abstract}

\begin{abstract}
Medical examination, as a very practical subject, is an important part of the teaching content of medical education in our country. Therefore, in order to adapt to the development of medical technology in the new period, medical colleges and universities in our country constantly improve the teaching mode of education. In order to train more excellent medical personnel in the new period, the "21" talent training plan of "teaching and clinical integration" was carried out by adopting the teaching method of integrating the departments and subjects. This paper first analyzes the practice and innovation of the training of medical laboratory professionals under the mode of integration of departments and disciplines in order to explore the advantages of medical laboratory experiment teaching in this teaching mode.
\end{abstract}

\section{Introduction}

With the continuous progress of medical technology in the new period, medical equipment is also constantly improving, which puts forward higher requirements for medical laboratory students in our country. The traditional teaching methods alone can not meet the needs of current medical professionals, so, It is necessary for medical colleges and universities to carry out education and teaching reform. By virtue of its strong hardware resource advantage and high quality teachers, the teaching mode of integrating department and subject can provide students with convenient clinical practice channel, which can break through the bottleneck of medical laboratory teaching. To provide strong support for the training of medical laboratory professionals in the new period.

\section{Practice and Innovation of training Medical Laboratory Professionals under the Mode of Integration of departments and departments}

\subsection{The basic Management Model of the Integration of departments and departments}

The basic management model of the integration of departments and departments is the product of the rapid development of life science. At present, with the rapid development of life science, various high and new technologies are widely infiltrated into the clinic, which makes the content and situation of clinical work change greatly. Therefore, in order to adapt to this change as soon as possible, medical laboratory major began to explore a new teaching model, and strive to improve students' professional knowledge and experimental operation skills under the premise of the continuous development of medical technology. To meet the needs of clinical trial industry for talent.

The "21" talent training mode of "integration of teaching and clinical practice" means that the first 2 years should focus on training students' basic professional knowledge and paying attention to the general education of students. Humanities education and professional basic knowledge education enable students to master the most basic clinical laboratory knowledge and communication skills. The latter 1 years refers to the practice of students entering the clinical trial post of affiliated hospital after completing the basic knowledge education, which mainly trains the students' time operation ability of specialized courses. 


\subsection{The course system with distinctive characteristics is constructed through the teaching mode of integrating the department with the subject.}

With the continuous development of medical laboratory technology, medical laboratory work began to require more and more technical personnel, which requires medical colleges and universities to cope with the rapid development of medical testing technology, education and teaching reform. The teaching mode of the integration of departments and subjects is a new system of laboratory teaching for medical laboratory specialties. The general education curriculum, professional basic courses and professional courses are divided according to different learning stages, and teachers of different professional levels teach. General education courses and professional courses are taught by teachers of basic courses in clinical medicine, while courses in medical laboratory techniques are taught by laboratory physicians, who work in The mastery of experimental technology is far greater than that of other professional teachers. Therefore, it is of great significance not only to the students' technical study but also to the future development of medical colleges and universities. The teaching mode of integrating departments and subjects fully shows the teaching characteristics of double-qualified teachers, exerts the specialty of different teachers, makes the future combination of basic courses and professional courses more professional, and brings higher timeliness to medical laboratory teaching. It greatly improves the efficiency of medical laboratory teaching, increases the employment rate of students in clinical trials, and lays a solid foundation for the future development of students.

\section{Advantages of Experimental Teaching of Medical Laboratory under the Mode of Integration of Department and subject}

There are many advantages in medical laboratory experiment teaching, including hardware, teachers and clinical practice.

\subsection{Hardware advantage}

At the present stage, with the rapid development of the social economy and the rapid development of information technology, the computer technology and the automation technology have been applied to all walks of society. Microscope and other equipment, so that students can enjoy the learning and contact with advanced medical equipment. For example, in the experimental teaching of clinical biochemistry and clinical microorganism, teachers can demonstrate the teaching by eliminating the fully automatic microbiological identification instrument. Firstly, the students can master the basic operating principle of the instrument and let the students test it in person. This not only effectively improves the utilization rate of resources, but also fully enables students to contact medical instruments and the fear that customer service is afraid to touch, so that students can better understand the function and use of the testing instruments before entering clinical testing practice. To a large extent, this reflects the advantages of the teaching mode of the integration of departments and subjects. Potential, to a certain extent, to solve the shortage of resources.

\subsection{Teacher advantage}

To effectively improve the efficiency of medical laboratory teaching, it is far from enough to rely on advanced hardware facilities, and the allocation of high quality teachers' resources is also indispensable in medical laboratory teaching. The teaching of medical laboratory under the teaching mode of the integration of department and subject emphasizes the comprehensive and advanced nature of the subject, and requires teachers to connect the professional theoretical knowledge with the practice of experimental teaching, instead of separating theory from practice. It is necessary for professional teachers to have theoretical knowledge of medical laboratory specialty and other knowledge related to this experiment, and to be proficient in the operation of experimental equipment. Therefore, the teaching mode of integrating departments with subjects is put forward to medical laboratory teachers. A higher demand has been made.

The professional teachers in the teaching mode of the integration of departments and subjects all 
come from the clinical test workers. They have rich clinical laboratory experience, which means that the theoretical knowledge learned by the students can be connected with the clinical tests in the teaching. In addition, these teachers have had extensive contact with experimental operations in their work, the latest research and progress in the analysis of experimental results and clinical tests, and they are quite familiar with clinical laboratory work, and most of them are editor-in-chief of medical laboratory textbooks in the new era. Not knowing much about the contents of books and teaching them to students not only have great advantages in helping students to learn professional knowledge, but also have great advantages in mastering experimental exercises for students. It also has remarkable results. For example, in the course of deepening clinical teaching, teachers can display clinical test cases to students through their own clinical trial experience, and make analysis of the results, so as to fully expand students' thinking and stimulate students' ability to actively consult information. Ability to collaborate, as well as comprehensive presentation. In this process, the students are familiar with the specific process of clinical testing, cultivate the students' good thinking ability and practical ability, so that the students can grasp the knowledge points in the books more firmly, so as to enhance the students' interest in learning. These are the advantages of a strong faculty.

\subsection{Clinical practice advantage}

The application of the mode of integration of departments and subjects provides good practice opportunities for medical laboratory students. After completing the basic theory and professional courses of medical laboratory, students can go directly to the clinical laboratory of affiliated hospitals for practical work. Through this model, the students can directly operate the clinical test equipment, inculcate all the knowledge they have learned in the school into the practical operation, and understand the basic technology of medical examination and the basic principle of the instrument operation. The teacher who led the student practice was the former experimental teaching teacher because they had been exposed to clinical trial work, and they were familiar with the procedure of clinical trial operation Also understand the students' learning situation, can better grasp the students' misoperation mistakes, and if necessary, can also supplement the relevant content. In addition, these supplementary contents can be used as the content of the next Linchuan experimental teaching textbook. It makes clinical experiment teaching develop continuously. After the students' practice, the teachers should also summarize the practice of the students, put forward the problems that students should pay attention to in the process of practice, let the students better combine the theoretical knowledge with the clinical trials, and consolidate the knowledge and operation skills.

\section{Conclusion}

To sum up, the teaching model of the integration of department and subject provides strong hardware advantages and high quality teachers for medical laboratory experiment teaching, and provides students with the opportunity of clinical trial. Therefore, through the attempt of this model, It is not only conducive to breaking through the bottleneck of professional development, but also of great significance to the sustainable development of medical laboratory specialty, and provides a continuous stream of high-quality talents for clinical trial work in the future.

\section{Acknowledgement}

In this paper, the research was sponsored by Project of Scientific Research of Binzhou Polytechnic College (Project No. 2013XYKT121) and Project of Scientific Research of Binzhou (Project No. 2013KT11). 


\section{References}

[1] Xie Yifu, Yan Chengjing, Jung Guodong, Qian Guohua, Ni Fang, Wang Fang. Teaching characteristics and experience of Clinical Laboratory Instruments and techniques in the Mode of Integration of departments and departments [J]. International Journal of Laboratory Medicine, 2018,39 (06): 765-766 768.

[2] Zhang Yuqiang, Xia Bingyan, Yan Pihong, Wang Tao, Zhou Yuming, feudal Kai, Tan Hongwei, Su Zhenguo. Practice and Innovation of Talent training Model of "Integration of departments and departments" [J]. Chinese Medical Education Technology, 2018,32 (01): 32-34.

[3] Zuo Xiufeng, Li Minxia, Liu Juan, Hu Lilei, Qiu Dong. The practice of integrating Department and subject in the training of Medical Laboratory students' skills [J]. China higher Medical Education, 2017 (09): 52-53.

[4] Zhao Liping, Quan Zhibo, Cui Yang, Wang Li, Li Yankui. Construction and practice of the innovative Experimental area of the training Mode of the Department of Medical Laboratory Technology combined with the Department of Science and Technology [J]. International Journal of Laboratory Medicine,2017,38 (16): 2326-2327.

[5] Zhao Qingjiang, he Qiurong. Discussion on the advantages of Medical Laboratory experiment Teaching in the Mode of Integration of Department and subject [J]. Huaxi Medical Med,2009,24 (09): 2386-2388. 